\title{
Efeito da faixa-filtro na retenção de atrazina em escoamento superficial
}

\author{
Maria T. Falsetti Ludovice ${ }^{1}$, Denis M. Roston² \& José Teixeira Filho ${ }^{3}$
}

\begin{abstract}
1 Departamento de Água e Solo, Faculdade de Engenharia Agrícola, FEAGRI/UNICAMP. CP 6011, CEP 13083-970, Campinas, SP. Fone: (19) 3788-1020, Telefax: (19) 3788-1010. E-mail: matereza@agr.unicamp.br (Foto)

2 Departamento de Água e Solo, FEAGRI/UNICAMP. E-mail: denis@agr.Unicamp.br

${ }^{3}$ Departamento de Água e Solo, FEAGRI/UNICAMP. Email: jose@agr.unicamp.br
\end{abstract}

Protocolo 152 - 17/10/2002 - Aprovado em 27/6/2003

\begin{abstract}
Resumo: O presente estudo avaliou a eficácia de faixas-filtro de comprimentos de 0, 5 e $10 \mathrm{~m}$ na redução de atrazina em água de escoamento provinda de áreas cultivadas com milho, gerada por 4 chuvas simuladas. Na faixa-filtro utilizou-se braquiária (Brachiaria decumbens) como elemento de retenção da atrazina. A diminuição dos valores mobilizados e transportados de atrazina encontrados, demonstrou a eficiência dessa faixa. A faixa de $5 \mathrm{~m}$ reduziu, em relação à parcela sem faixa ( 0 m de comprimento), nos 4 eventos de chuva simulada, um total de $73,8 \%$ da atrazina aplicada ao solo. Na de $10 \mathrm{~m}$ os valores foram maiores, tendo havido redução de $89,7 \%$, a qual foi obtida a partir do aumento efetivo da infiltração da água do escoamento superficial na faixafiltro. Quanto aos valores de concentração, não se observaram reduções efetivas, ficando evidente que a faixa vegetada pode ser eficiente na redução de substância em diluição na água, como no caso da atrazina sem provocar, no entanto, diminuição das concentrações presentes.
\end{abstract}

Palavras-chave: faixa-filtro, escoamento superficial, atrazina

\section{Effect of filter strip on atrazine retention in runoff}

\begin{abstract}
The objective of this study was to evaluate the removal of atrazine in runoff waters from areas cultivated with corn, utilizing 0,5 and $10 \mathrm{~m}$ length vegetative filter strips. The runoff was generated by 4 simulated rains. The filter strips were cultivated with Brachiaria decumbens, which acts as an atrazine retention element. The $5 \mathrm{~m}$ length filter had $73,8 \%$ reduction of atrazine compared to control (without filter). The $10 \mathrm{~m}$ width filter had a reduction of $89,7 \%$. These percentages of reduction were obtained due to an increase of water infiltration in the filter soil. The experiment demonstrated an efficient reduction of atrazine diluted in water, although the concentration did not suffer important reduction.
\end{abstract}

Key words: filter strip, runoff, atrazine

\section{INTRODUÇÃO}

A intensificação do uso dos pesticidas no Brasil tem gerado uma ameaça não só aos recursos hídricos mas, também, à integridade dos ecossistemas. Algumas práticas conhecidas por Best Management Practices - BMP, envolvem alterações na hidráulica do escoamento superficial (Misra et al., 1996), seu volume e velocidade antes de adentrarem um curso d'água. Entre essas práticas tem-se os tampões, faixas vegetadas, localizadas ao longo do perímetro da área cultivada ou das margens dos corpos d'água para reduzir a velocidade do escoamento superficial (Dozier, 1999).

Esse sistema é normalmente utilizado como parte de uma prática conservacionista e em conjunto com a mata ciliar. Os trabalhos relatados na literatura sobre a eficiência da faixa-filtro têm demonstrado ser esta uma alternativa conservacionista tecnicamente viável, tendo em vista os resultados encontrados.

A agricultura é o setor que causa maior impacto nos recursos hídricos e a sua intensificação tem concorrido para a degradação da qualidade desses recursos, em especial provocada pelo escoamento de resíduos, efluentes e insumos agrícolas que podem alcançar as águas superficiais e, também, em menor grau, as águas subterrâneas.

O material particulado contido no escoamento superficial é a maior fonte de poluição, pois químicos e nutrientes são associados à erosão de partículas menores de sedimento (Deletic, 1999). Os poluentes ligados ao sedimento são carreados para os corpos de água, causando impactos como assoreamento 
das margens dos corpos d'água, aumento da poluição, da turbidez e da temperatura da água, afetando negativamente a fauna e flora aquática.

A atrazina, herbicida alvo desta pesquisa, é um dos mais usados em todo o mundo, principalmente na cultura de milho e tem sido detectada em águas superficiais e também subterrâneas, em concentrações preocupantes. Em solos arenosos, pode sofrer lixiviação relativamente rápida, atingindo profundidades consideráveis (Pessoa et al., 1998). Esse composto apresenta baixo potencial de bioacumulação e moderadas adsorção e mobilidade em solo e, sendo solúvel, tem sido encontrado em águas superficiais e no perfil do solo (Atrazine, 1993).

Hermes et al. (1995), em estudo no qual avaliaram o grau de transporte superficial de 2,4-D, atrazina, trifluralina e do inseticida aldicarb, constataram a conduta desses compostos no solo. $\mathrm{O}$ experimento foi instalado em quatro parcelas de $3 \times 10 \mathrm{~m}$, em área de solo Podzólico Vermelho-Amarelo de textura arenosa. As doses aplicadas foram as recomendadas para a cultura de milho. Foram simuladas duas chuvas de $60 \mathrm{~mm} \mathrm{~h}^{-1}$, durante $30 \mathrm{~min}$, com intervalo de $24 \mathrm{~h}$. Durante as simulações de chuva, as amostras de água de escoamento foram coletadas a cada $5 \mathrm{~min}$. A atrazina e 2,4-D apresentaram comportamento semelhante em ambas as chuvas, com decréscimo de concentração na água de enxurrada ao longo do tempo, ocorrendo maior perda por escoamento superficial na primeira chuva. A trifluralina e o aldicarb apresentaram comportamento oposto aos desses compostos.

Mesmo que decréscimos tenham ocorrido na concentração de atrazina, sua aplicação vem aumentando anualmente, o que, sem dúvida, provocará um incremento em sua concentração na água superficial (Laroche \& Gallichand, 1995).

De modo geral, os herbicidas têm sido estudados associados à faixa-filtro, no sentido de se procurar minimizar sua concentração, evitando a poluição de recursos hídricos. O desempenho da faixa na redução de poluentes depende também do tipo dos mesmos, da vegetação e da largura da referida faixa (Schmitt et al., 1999).

Fluxo uniforme é essencial para a efetividade da faixa, pois a formação de canais afeta sua eficiência na retenção de sedimentos e nutrientes (National, 1998, Filter, 2000, Leeds et al., 2001).

Dos vários trabalhos desenvolvidos sobre redução de herbicidas, nutrientes e sedimentos por faixas vegetadas, o de Hoffman et al. (1999) priorizou o estudo da influência da faixa na remoção na referida faixa, enfatizando a remoção de atrazina, uma vez que esse herbicida é amplamente utilizado no controle de plantas invasoras em cultura de cereais no sul dos Estados Unidos. Os estudos foram conduzidos em nove bacias hidrográficas, analisando-se três sistemas de plantio: plantio convencional de milho com faixa-filtro, semeada com gramínea; plantio convencional de milho, com faixa-filtro plantada com trigo e plantio convencional de milho, sem faixa-filtro. Esses sistemas foram repetidos três vezes. As análises do herbicida foram feitas em amostras de água de escoamento e de solo das faixas. Os resultados indicaram que as faixas filtro plantadas com bermuda grass retiveram $57 \%$ do escoamento e aquelas plantadas com trigo, retiveram $50 \%$. Esses dados indicaram que volumes significativos de enxurradas foram retidos pelas faixas vegetadas diminuindo, assim, o risco de contaminação das águas superficiais com atrazina.

Em trabalho conduzido em Wisconsin com Poa radensis L., Pearce et al. (1997) demonstraram que a eficiência da faixa na retenção de sedimentos está relacionada mais a seu comprimento que à altura de sua vegetação.

Neste trabalho avaliou-se a eficácia de faixas vegetadas de diferentes comprimentos $(0,5$ e $10 \mathrm{~m})$ na retenção de atrazina na cultura do milho, comparando-se os resultados obtidos nas três comprimentos, em condições de clima tropical e solos com características da região oeste do Estado de São Paulo, Brasil.

\section{MATERIAL E MÉTODOS}

O experimento foi conduzido em 9 parcelas, medindo $10 \times 3$ m, em 2000, 2001 e 2002, na Estação Experimental do Instituto Agronômico de Campinas-IAC, no município de Pindorama, Estado de São Paulo, Brasil, localizada a $21^{\circ} 13^{\prime}$ de latitude sul e $48^{\circ} 55^{\prime}$ de longitude oeste, apresenta temperatura média anual de $22,8^{\circ} \mathrm{C}$, precipitação média anual de $1.390,3 \mathrm{~mm}$ e umidade relativa do ar média de $71,6 \%$. Conforme a classificação de Köppen, o clima se enquadra no tipo Aw, definido como tropical úmido, com estação chuvosa no verão e seca no inverno.

As parcelas cultivadas com milho apresentam declividade de $6 \%$ em um solo Argissolo eutrófico, A moderado, textura arenosa/média - Unidade Pindorama. O relevo da região é ondulado, sendo que as altitudes variam de 498 a $594 \mathrm{~m}$. As parcelas experimentais foram constituídas por faixas de 0,5 e $10 \mathrm{~m}$ (Figura 1), em triplicata, cultivadas com braquiária (Brachiaria decumbens). A altura da gramínea em questão foi mantida em $20 \mathrm{~cm}$. Essas parcelas foram fechadas por chapas em metal galvanizado para evitar a entrada de escoamento nas parcelas.

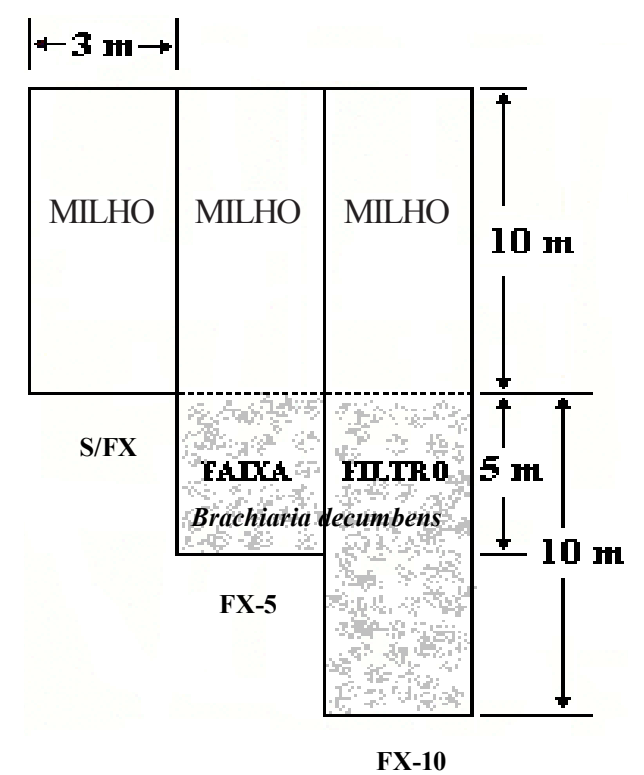

Figura 1. Esquema da faixa-filtro (S/FX Faixa-Filtro de $0 \mathrm{~m}, \mathrm{FX}-5$ faixa-filtro de $5 \mathrm{~m}$ e FX-10 faixa-filtro de $10 \mathrm{~m}$ ) 
Para avaliar a eficiência da retenção dos nutrientes em estudo utilizou-se a faixa-filtro de $0 \mathrm{~m}$ como referência para comparação das faixas de $5 \mathrm{~m}$ e da faixa de $10 \mathrm{~m}$.

\section{Simulador de chuva}

O escoamento gerado por chuva artificial aplicada por simulador tipo Swanson, com 10 braços rotativos a $4 \mathrm{rpm}$ sob uma pressão de 0,4 bar, foi coletado manualmente via tubulação de PVC adaptada nas soleiras localizadas na parte inferior das parcelas. Utilizou-se chapa metal galvanizado para limitar as parcelas, tanto nas laterais como em sua parte superior. Para evitar a possível interferência de chuva natural construiu-se, sobre cada parcela, uma estrutura para suportar uma cobertura de plástico utilizado em estufa.

A intensidade dos eventos simulados foi de $60 \mathrm{~mm} \mathrm{~h}^{-1}$, aplicados em cada parcela durante $1 \mathrm{~h}$ e $50 \mathrm{~min}$. Foram simulados 4 eventos chuvosos, o primeiro realizado no dia 14/4/2000, o segundo no dia 17/4/2000, e após uma interrupção de 8 dias, o terceiro no dia 25/4/2000 e o último, 28/4/2000, havendo um intervalo mínimo de $24 \mathrm{~h}$ entre o primeiro e o segundo e, entre o terceiro e o quarto. O primeiro evento teve início imediatamente após a aplicação de atrazina, devido à possibilidade desse herbicida ser vulnerável ao processo de fotodecomposição (Lin et al., 1999) .

\section{Aplicação de atrazina}

O herbicida utilizado foi o Primestra Gold, fabricado pela Syngenta, sendo a atrazina aplicada na dose de 1,295 $\mathrm{g} \mathrm{ha}^{-1}$ do princípio ativo após o plantio e antes da primeira chuva, que teve início em seguida à aplicação da atrazina. Utilizou-se um pulverizador costal de $20 \mathrm{~L}$ ou ponta de pulverização de jato plano descentrado TeeJet OC-06, para capacidades menores.

\section{Medida de vazão}

Para cada evento e a partir do início do escoamento superficial, as vazões em cada parcela foram medidas em intervalos de $5 \mathrm{~min}$. Para medição da vazão utilizou-se uma proveta de $1 \mathrm{~L}$, fixando-se o volume $(1 \mathrm{~L})$ e medindo o tempo necessário para a obtenção desse volume.

\section{Amostragem de água}

Uma amostra de água de $1 \mathrm{~L}$ em cada parcela foi coletada em intervalos de 5 min para cada evento, a partir do início do escoamento. Ao término de cada evento determinou-se a alíquota de cada amostra coletada ao longo do escoamento para formar a amostra composta de $1 \mathrm{~L}$ da parcela em estudo. Esta alíquota é função da vazão medida nos intervalos de tempo correspondentes. Assim, para cada evento uma única amostra composta foi constituída para cada parcela. As amostras compostas foram analisadas pelo Instituto de Química, da Universidade Estadual de Campinas, por Cromatografia Líquida de Alta Eficiência (EMBRAPA, 1998).

\section{Procedimento analítico}

Técnica utilizada e equipamento: extração líquido-líquido, pré-concentração e análise em Cromatógrafo Líquido de Alta Eficiência Hewlett Packard Modelo: 1090 Série II/M Diode Array.
Extração líquido-líquido e pré-concentração: alcalinizaramse $100 \mathrm{~mL}$ da amostra com $25 \mu \mathrm{L}$ de $\mathrm{NaOH} 4 \mathrm{~N}$. Efetuaram-se 3 extrações de $20 \mathrm{~mL}$, com diclorometano em funil de separação. Os extratos foram colocados em balões de fundo redondo e evaporados em rota evaporador, até volume de aproximadamente $5 \mathrm{~mL}$. Os extratos foram transferidos para béqueres de $10 \mathrm{~mL}$. Deixou-se evaporar até à secura. Adicionou-se $1 \mathrm{~mL}$ de fase móvel e se colocou em banho ultra-sônico durante $5 \mathrm{~min}$. As soluções foram filtradas em membranas $0,45 \mu \mathrm{m}$ e transferidas as soluções para frascos de injeções do HPLC. Efetuou-se um branco com água de torneira e se executou um teste de recuperação do método de extração.

Condições cromatográficas: Coluna Nova Pak C18 3,9 x 150 mm; Fase Móvel: água e acetonitrila; Detector: UV 220 nm;

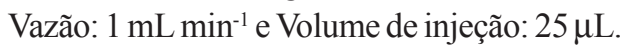

\section{RESULTADOS E DISCUSSÃO}

Os resultados dos volumes gerados nas parcelas pela aplicação da precipitação simulada, estão apresentados na Figura 2. A intensidade da precipitação simulada de $60 \mathrm{~mm} \mathrm{~h}^{-1}$ e duração de $110 \mathrm{~min}$, resultou em um volume total aplicado de $3300 \mathrm{~L}$ por parcela. Na Figura 2 pode-se observar, para a parcela sem faixafiltro, que para o primeiro evento o volume médio de escoamento superficial gerado foi de $233 \mathrm{~L}$. Para este evento, o coeficiente de escoamento superficial (CES) calculado foi de 0,07 , cujo valor relativamente baixo se deve ao tipo de solo, o qual apresenta alta capacidade de infiltração de água. O volume escoado superficialmente no primeiro evento, na parcela sem faixa-filtro, apresentou valor máximo medido $30 \%$ superior em relação à média dos escoamentos e valor mínimo inferior a $25 \%$, o que reflete as variabilidades locais da estrutura do solo nas parcelas (Figura 2). Esta variabilidade local pode ser verificada nas outras parcelas e nos demais eventos. Para o primeiro evento, observou-se nas parcelas de $5 \mathrm{~m}$ de faixa-filtro, um volume médio de $46 \mathrm{~L}$ $(\mathrm{CES}=0,014)$; nas parcelas de $10 \mathrm{~m}$ de faixas, o volume médio medido foi calculado igual a $38 \mathrm{~L}(\mathrm{CES}=0,012)$.

No primeiro evento ocorreu decréscimo, em relação à faixa de $0 \mathrm{~m}$, de aproximadamente $80 \%$ no volume médio de escoamento, na faixa de $5 \mathrm{~m}$ e de $84 \%$ na faixa de $10 \mathrm{~m}$, comprovando a eficiência da faixa-filtro na redução da velocidade de escoamento da água (Dillaha et al., 1989; Muscutt, 1993; Misra et al., 1996) pela resistência imposta pela vegetação da faixa-filtro (Arora et al., 1996), o que resulta em perda da capacidade de transporte (Barfield et al., 1998). Os volumes de escoamento superficial apresentaram tendência decrescente ao longo dos eventos, devido ao aumento progressivo da umidade no solo. Este fato pode ser verificado quando se observa, no quarto evento, o resultado do volume médio de escoamento para as parcelas sem faixa-filtro, que foi $372 \mathrm{~L}(\mathrm{CES}=0,11), 243$ $\mathrm{L}$ faixa de $5 \mathrm{~m}(\mathrm{CES}=0,07)$ e de $126 \mathrm{~L}$ faixa de $10 \mathrm{~m}(\mathrm{CES}=0,04)$.

O fluxo superficial é um significativo mecanismo de transporte de sedimentos, poluentes e pesticidas, e a faixa-filtro uma barreira que minimiza a ação dos mesmos. Os resultados obtidos para atrazina confirmam esta assertiva e podem ser 


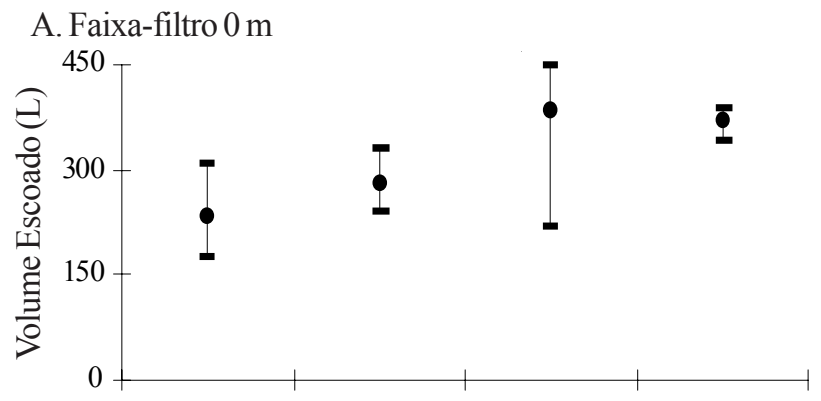

B. Faixa-filtro $5 \mathrm{~m}$

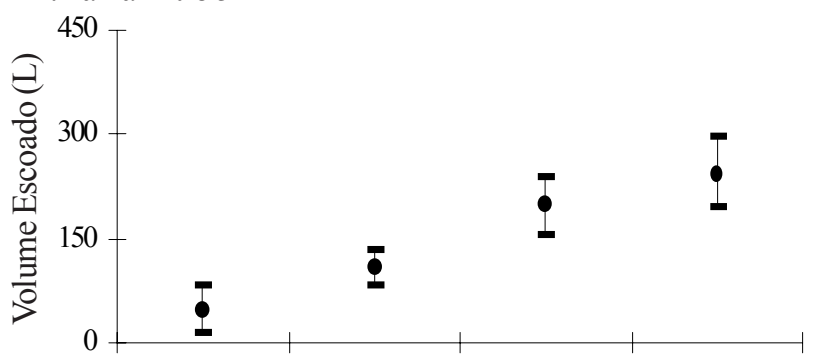

C. Faixa-filtro $10 \mathrm{~m}$

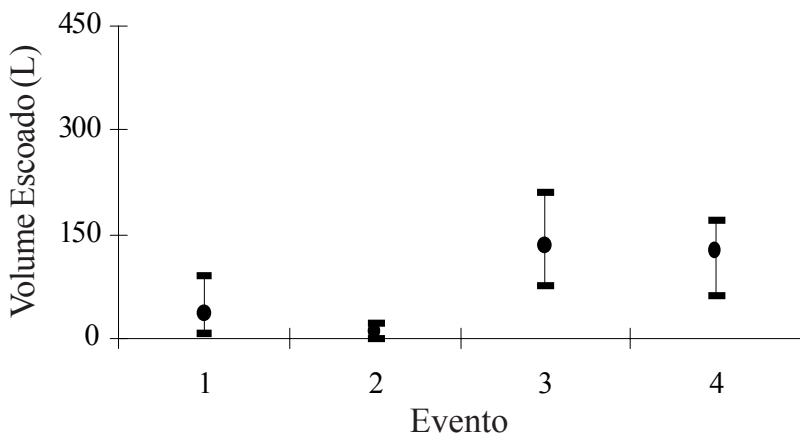

Figura 2. Volume total escoado superficialmente em cada evento e parcela para uma intensidade de precipitação simulada de $60 \mathrm{~mm} \mathrm{~min}^{-1}$ e duração de $110 \mathrm{~min}$. Os círculos representam os valores médios de três parcelas com as mesmas características de comprimento de faixa-filtro. As barras representam os valores máximos e mínimos observados

observados nas Figuras 3 e 4 . A eficiência na retenção de atrazina pelas faixas pode ser obtida comparando-se o resultado das amostras coletadas das parcelas com faixas de $0 \mathrm{~m}$ com o daquelas com faixas de 5 e $10 \mathrm{~m}$ de comprimento. Nessas faixas houve decréscimo na concentração média de atrazina no efluente do primeiro evento (Figura 2). As reduções obtidas foram de $21 \%$ e $56 \%$ respectivamente, para as faixas de 5 e $10 \mathrm{~m}$; entretanto, os três eventos posteriores não mostraram nenhuma redução, tendo havido, em alguns casos até um aumento nas concentrações nas parcelas com faixa-filtro. Os resultados obtidos podem ser creditados ao fato de que, no primeiro evento, ocorreu armazenamento da atrazina nas faixas-filtro. Nos demais eventos, o efeito residual do herbicida armazenado foi mobilizado pelo escoamento superficial nas faixas-filtro de 5 e 10 m obtendose, assim, aumento das concentrações nas respectivas faixas. Na Figura 4 verifica-se, com mais detalhes, este efeito, observando-se as concentrações médias de cada evento. Tal resultado demonstrou que as faixas-filtro não diminuíram as concentrações das substâncias, concorrendo apenas para que ocorra sua diluição na água dos escoamentos superficiais (Chaubey et al., 1995). Por outro lado, as faixas atenuaram as massas das substâncias, como se verifica na Figura 5, ao se observar as reduções das massas transportadas na saída das parcelas. O transporte de massa para alguns poluentes pode ser reduzido significantemente pela faixa-filtro (Lim et al., 1998). Os resultados obtidos neste trabalho confirmam a eficiência da faixa na retenção de substâncias em diluição, não por um processo mecânico mas sua efetiva retenção pela faixa-filtro, a partir do processo de infiltração.

Na Figura 5 observou-se a eficiência da retenção de massa de atrazina no experimento. No primeiro evento, verifica-se redução de $85 \%$ de atrazina nas parcelas com $5 \mathrm{~m}$ de faixa-filtro e de $93 \%$ nas faixas com $10 \mathrm{~m}$. Este aumento na redução de atrazina se deve ao decréscimo dos volumes de escoamento superficial (Schmitt et al., 1999). A retenção de atrazina nas faixas-filtro diminuiu rapidamente com a aplicação de chuvas simuladas, tornando-se sem efeito a partir do terceiro evento. Considerando-se as quantidades mobilizadas e transportadas para a saída das parcelas, constatou-se que, em média, 19,5 mg de atrazina saíram das parcelas sem faixa-filtro, enquanto $5,1 \mathrm{mg}$ e 2,0 mg de atrazina partiram das parcelas com 5 e $10 \mathrm{~m}$, respectivamente. A redução final obtida nas faixas foi 73,8 e $89,7 \%$ de atrazina, levando-se em conta as faixas de 5 e $10 \mathrm{~m}$,
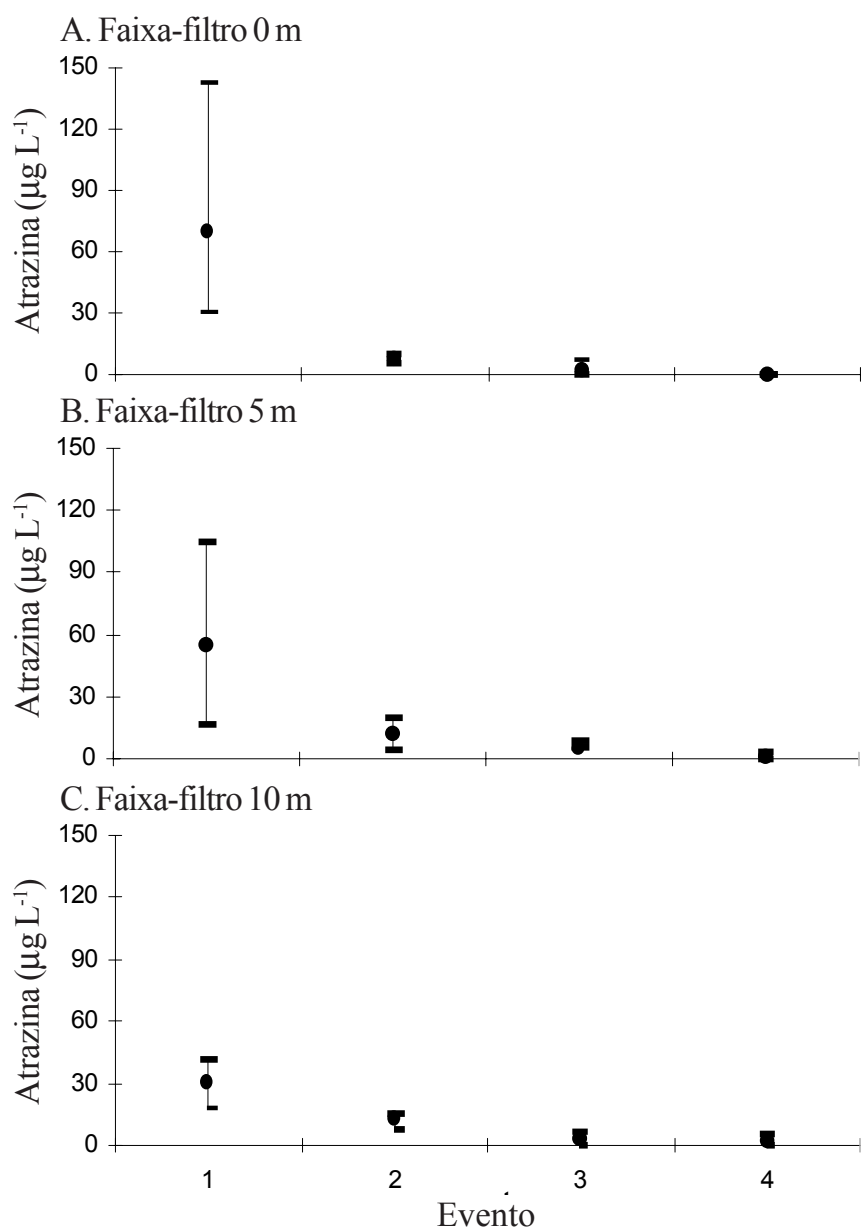

Figura 3. Concentração de atrazina das amostras compostas em cada evento e parcela para uma intensidade de precipitação simulada de $60 \mathrm{~mm} \mathrm{~min}^{-1}$ e duração de $110 \mathrm{~min}$. Os círculos representam os valores médios de três parcelas com as mesmas características de comprimento de faixa-filtro. As barras representam os valores máximos e mínimos observados 


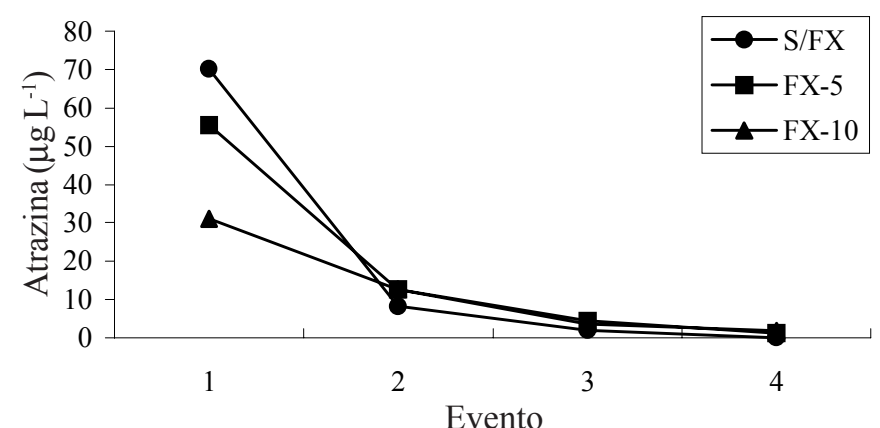

Figura 4. Concentração média de atrazina das amostras compostas em cada evento e parcela, para uma intensidade de precipitação simulada de $60 \mathrm{~mm} \mathrm{~min}^{-1}$ e duração de $110 \mathrm{~min}$ (S/FX parcela sem faixa-filtro, FX-5 faixa-filtro de 5 m e FX-10 faixa-filtro de $10 \mathrm{~m}$ )

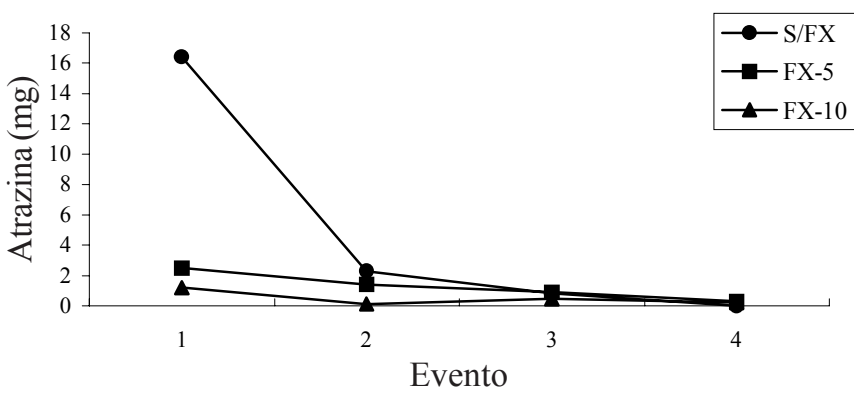

Figura 5. Quantidade média em massa de atrazina das amostras compostas em cada evento e parcela, para uma intensidade de precipitação simulada de $60 \mathrm{~mm} \mathrm{~min}^{-1}$ e duração de $110 \mathrm{~min}$ (S/FX parcela sem faixa-filtro, FX-5 faixa-filtro de 5 m e FX-10 faixa-filtro de $10 \mathrm{~m}$ )

respectivamente. O desempenho da faixa vegetada depende, em grande parte, do tipo de contaminante, sendo que os adsorvidos ou ligados a sedimentos sofrem muito maior redução que os dissolvidos, como nitrato, fósforo dissolvido, brometo, atrazina e alachlor (Schmitt et al., 1999).

Em termos de eficiência de comprimento, a faixa de $10 \mathrm{~m}$ mostrou não ter praticamente nenhum efeito adicional importante no transporte de massa de atrazina em relação à faixa de 5 m. Assim, os mecanismos de retenção não se estabelecem a partir de um modelo linear (Arora et al., 1996). Este fato demonstra a necessidade do estudo de outros comprimentos de faixa, para a definição de modelos, que possam determinar a relação da largura com a eficiência de retenção para cada caso particular.

\section{CONCLUSÕES}

1. Esses resultados confirmam a eficiência das faixas-filtro vegetadas na redução de atrazina mobilizada pelo escoamento superficial.

2. A diminuição dos impactos dos insumos agrícolas nos recursos hídricos apresenta atualmente um dos maiores desafios para os pesquisadores e técnicos no controle da qualidade de água dos cursos de água. Assim, as faixas vegetadas se constituem em uma alternativa para o controle de carga difusa de produtos fotossanitários utilizados na agricultura.

\section{AGRADECIMENTOS}

À FAPESP-Fundação de Amparo à Pesquisa no Estado de São Paulo, pelo financiamento do projeto, e à Estação Experimental de Agronomia de Pindorama, do Instituto Agronômico de Campinas, pelo apoio logístico.

\section{LITERATURA CITADA}

Arora, K.; Mickelson, S.K.; Baker, J.L.; Tierney, D.P.; Peters, C.J. Herbicide retention by vegetative buffer strips from runoff under natural rainfall. Transactions of ASAE, St Joseph, v. 39, n.6, p.2155-2162, 1996.

Atrazine Seminar, Ciba-Geigy, Brazilia, v.1, 1993, 121 p.

Barfield, B.J.; Blevins, R.L.; Fogle, A.W.; Madison, C.E.; Inamdar, D.I.; Evangelou, V.P. Water quality impacts of natural filter strips in karst areas. Transaction of ASAE, St. Joseph, v.41, n.2, p.371-381, 1998.

Chaubey, I.; Edwards, D.R.; Daniel, T.C.; Moore, P.A. J.; Nichols, D.J. Effectiveness of vegetative filter strips in controlling losses of surface-applied poultry litter constituents. Transactions of ASAE, St. Joseph, v.38, n.6, p.1687-1692, 1995.

Deletic, A. Sediment behaviour in grass filter strips. Water Science Technology, London, v.39, n.9, p.129-136, 1999.

Dillaha, T.A.; Reneau, R.B.; Mostaghimi, S.; Lee, D. Vegetative filter strips for agricultural nonpoint source pollution control. Transactions of ASAE, St. Joseph, v.32, n.2, p.513-519, 1989.

Dozier, M.C. Effectiveness of Bermuda grass (Cynodon dactylon L.) in reducing off-target losses of atrazine and metolachlor in surface runoff. Texas: Texas A\&M University, 1999. 85p. PhD. Thesis

EMBRAPA - Empresa Brasileira de Pesquisa Agropecuária. Impacto ambiental e suas implicações sócioeconômicas da Agricultura intensiva em água subterrânea. Jaguariúna: Embrapa Meio Ambiente, 1998, 36p. Relatório Final

Filter, Strip. http:/www.ctic.purdue.edu/BMPs/Choice7.html. Acesso: 07/02/2000.

Hermes, L.C.; Ligo, M.A.V.; Souza, M.D.; Vieira, S.R.; Abakerly, R.B.; Castro, O.M. Perda por deflúvio superficial de 2,4-D, atrazina, aldicarb sulfóxido e trifluralina em solo podzólico vermelho-amarelo. In: Congresso Brasileiro de Ciência do Solo, 25, 1995, Viçosa. Anais..., p.2415-2416, 1995.

Hoffman, D.W.; Gerik, T.J.; Richardson, C.W. Use of contour strip cropping as a best management practice to reduce atrazine contamination of surface water. http://waterhome. tamu.edu/curre...project/filterstripdescription/index.html. Acesso: 05/03/1999.

Laroche, A.M.; Gallichand, J. Analisys of pesticide residues in surface and groundwater of a small watershed. Transactions of ASAE, St. Joseph, v.38, n.6, p.1731-1736, 1995.

Lee, D.; Dillaha, T.A.; Sherrard, J.H. Modeling phosphorus transport in grass. Journal of Environmental Engineering, Reston, v.115, n.2, p.409-427, 1989. 
Leeds, R.; Brown, L.C.; Sulc, M.R.; Lieshout, L.V. Vegetative filter strips: Application, installation and maintenance. AEX467-94. http://ohioline.ag.ohio-state.edu/aex-fact/0467.html. Acesso: 10/11/2001.

Lim, T.T.; Edwards, S.R.; Workman, S.R.; Larson, Dunn, L. Vegetated filter strip removal of cattle manure constituents in runoff. Transactions of the ASAE, St. Joseph, v.41, n.5, 1375-1381, 1998.

Lin, Y.J.; Karuppiah, M.; Shaw, A.; Gupta, G. Effect of simulated sunlight on atrazine and metolachlor toxicity of surface waters. Ecotoxicology and Environmental Safety, Amsterdam, v. 43, Issue 1, p.35-37, 1999.

Misra, A.K.; Baker., J.L.; Mickelson, S.K.; Shang, H. Contributing area and concentration effects on herbicide removal by vegetative filter strips. Transactions of ASAE, St. Joseph, v.39, n.6, p. 2105-2111, 1996.

Muscutt, A.D.; Harris, G.L.; Bailey, S.W.; Davies; D.B. Buffer zones to improve water quality: a review of their potential use in UK agriculture. Agriculture, Ecosystems and Environment, Amsterdam, v.45, p.59-77, 1993.
National Handbook of Conservation Practices - NHPC. Filter strip. http://www.oneplan.state.id....actices/Standards/ STDS18.htm. Acesso: 07/02/98

Pearce, R.A.; Trlica, M.J.; Leininger, W.C.; Smith, J.L.; Frasier, G.W. Efficiency of grass buffer strips and vegetation height on sediment filtration in laboratory rainfall simulations. Journal of Environmental Quality, Madison, v.26, p.139-144, 1997.

Pessoa, M.C.P.Y.; Gomes, M.A.F.; Nicollela, G.; Souza, M.D.; Cerdeira, A.L.; Monticelli, A. Simulação do movimento dos herbicidas hexazinone, diuron, atrazina, ametrina e simazina aplicados na cultura de cana-de-açúcar em solos da microbacia do Córrego Preto, Ribeirão Preto. Anais... Reunião Brasileira de Fertilidade do Solo e Nutrição de Plantas, 23; Reunião Brasileira sobre Micorrizas 7; Simpósio Brasileiro de Microbiologia do Solo 5, e Reunião Brasileira de Biologia do Solo 2. Caxambu, 1998. CD-Rom

Schmitt, T.J.; Dosskey, M.G.; Hoagland, K.D. Filter strip performance and processes for different vegetation, widths and contaminants. Journal of Environmental Quality, Madison, v.28, p.1479-1489, 1999. 